\title{
Beyond the project: building a strategic theory of change to address dementia care, treatment and support gaps across seven middle-income countries
}

This paper has been published in Dementia with the following citation:

Breuer E, Comas-Herrera A, Freeman E, et al. Beyond the project: Building a strategic theory of change to address dementia care, treatment and support gaps across seven middle-income countries. Dementia. July 2021. doi:10.1177/14713012211029105. You can access the published article here.

\section{Author list}

1. Erica Breuer, Post-doctoral research fellow, University of Newcastle, Australia; and Alan J. Flisher Centre for Public Mental Health, Department of Psychiatry and Mental Health, University of Cape Town, South Africa; erica.breuer@newcastle.edu.au

2. Adelina Comas-Herrera, Care Policy and Evaluation Centre, London School of Economics and Political Science, UK

3. Emily Freeman, Care Policy and Evaluation Centre, London School of Economics and Political Science, UK

4. Emiliano Albanese, Universià della Svizzerra Italiana, Lugano, and Faculty of Medicine, University of Geneva, Switzerland

5. Suvarna Alladi, National institute of Mental Health and Neuro Sciences, India

6. Rochelle Amour, Caribbean Institute for Health Research, The University of the West Indies, Jamaica

7. Sara Evans-Lacko, Care Policy and Evaluation Centre, London School of Economics and Political Science, UK

8. Cleusa P. Ferri, Department of Psychiatry, Universidade Federal de São Paulo, Brazil

9. Ishtar Govia, Caribbean Institute for Health Research, The University of the West Indies, Jamaica

10. Claudia Iveth Astudillo García, Psychiatric Care Services, Ministry of Health, Mexico

11. Martin Knapp, Care Policy and Evaluation Centre, London School of Economics and Political Science, UK

12. Michael Lefevre, Alzheimer's Disease International

13. Mariana López-Ortega, National Institute of Geriatrics, Mexico 
14. Crick Lund, Alan J. Flisher Centre for Public Mental Health, Department of Psychiatry and Mental Health, University of Cape Town, South Africa; and Centre for Global Mental Health, Institute of Psychiatry, Psychology and Neuroscience, King's College London, UK

15. Christine Musyimi, Africa Mental Health Research and Training Foundation, Kenya

16. David Ndetei, Department of Psychiatry, University of Nairobi, Africa Mental Health Research and Training Foundation, Kenya

17. Déborah Oliveira, Department of Psychiatry, Universidade Federal de São Paulo, Brazil

18. Tiffany Palmer, Caribbean Institute for Health Research, The University of the West Indies, Jamaica

19. Meera Pattabiraman, Alzheimer's and Related Disorders Society of India

20. Tara Puspitarini Sani. Alzheimer Indonesia and Department of Neurology. School of Medicine and Health Sciences. Atma Jaya Catholic University of Indonesia, Indonesia

21. Dubglas Taylor, Dementia Alliance International

22. Eileen Taylor, Dementia Alliance International

23. Imelda Theresia, Alzheimer Indonesia, Indonesia

24. Priya Treesa Thomas, National institute of Mental Health and Neuro Sciences, India

25. Yuda Turana. Alzheimer Indonesia and Department of Neurology. School of Medicine and Health Sciences. Atma Jaya Catholic University of Indonesia, Indonesia

26. Wendy Weidner, Alzheimer's Disease International

27. Marguerite Schneider, Alan J. Flisher Centre for Public Mental Health, University of Cape Town, South Africa

Contact details for lead author

Erica Breuer

University of Newcastle, Australia

Level 4 West, Hunter Medical Research Institute

Lot 1, Kookaburra Cct, New Lambton Heights

NSW 2305

Email: erica.breuer@newcastle.edu.au 


\section{Abstract}

Evidence from middle-income countries indicates high and increasing prevalence of dementia and need for services. However, there has been little investment in care, treatment or support for people living with dementia and their carers. The Strengthening Responses to Dementia in Developing Countries (STRIDE) project aims to build both research capacity and evidence on dementia care and services in Brazil, Indonesia, India, Jamaica, Kenya, Mexico, and South Africa. This paper presents the Theory of Change (ToC) approach we used to co-design our research project and to develop a strategic direction for dementia care, treatment and support, with stakeholders. ToC makes explicit the process underlying how a programme will achieve its impact. We developed ToCs in each country and across the STRiDE project with researchers, practitioners, people living with dementia, carers, and policymakers at different levels of government. This involved: 1) an initial ToC workshop with all project partners (43 participants); 2) ToC workshops in each STRiDE country (22-49 participants in each); 3) comparison between country-specific and overall project ToCs, 4) review of ToCs in light of WHO dementia guidelines and action plan; and 5) a final review. Our experiences suggest $T o C$ is an effective way to generate a shared vision for dementia care, treatment and support among diverse stakeholders. However the project contribution should be clearly delineated, and use additional strategies to ensure appropriate participation from people living with dementia and their carers in the ToC process. 


\section{Introduction}

In 2015, 46.8 million people were living with dementia worldwide (Prince, 2015). By 2050, this figure is expected to be 131.5 million, with more than two-thirds of this population living in low- and middle-income countries (LMICs) (Prince, 2015). While broad consensus exists about the importance of care, treatment and support systems for people with dementia and their unpaid carers, investment in developing these systems is inadequate in most world regions, particularly in LMICs.

The World Health Organization's Global action plan on the public health response to dementia was unanimously adopted by Member States at the $70^{\text {th }}$ World Health Assembly in 2017. Its first target is that 75 percent of countries will have adopted national dementia strategies or plans (NDPs) by 2025. At the end of December 2019, of the 32 member states that had NDPs, none were low-income countries and just six were middle-income countries (Alzheimer's Disease International, 2019a). To attain its ambitious goal and address the marked variation in dementia responses between countries, the WHO published a manual for developing NDPs (World Health Organization, 2017, 2018). Research is required in addition to the WHO manual in LMICs, to develop and operationalise NDPs.

Strengthening responses to dementia (STRiDE)

The Strengthening Responses to Dementia in Developing Countries (STRiDE) project aims to improve dementia care and support systems across seven middle-income countries by 1 ) building capacity to generate and use evidence, and 2) generating evidence to understand the impacts of dementia and needs of people living with dementia and their carers, in order to 3) support the development and/or implementation of NDPs(London School of Economics and Political Science, 2020) . Activities in the seven countries - Brazil, India, Indonesia, Jamaica, Kenya, Mexico, and South Africa are led by university- or research institute-based researchers and practitioners from national Alzheimer's or dementia associations. Other partners include Alzheimer's Disease International (ADI) and Dementia Alliance International (DAI). The overall project is led by researchers at the London School of Economics and Political Science, UK. The seven STRiDE countries were chosen because a) because there appeared to be good conditions for the project to have policy impact in those settings; (b) because the co-applicants either had existing collaborations and networks or it was considered possible to establish effective collaboration between researchers and NGOs; and c) to represent a range of circumstances (population size, land mass sizes, different Gross Domestic Product sector compositions) and degrees of progress towards meeting the challenges presented by dementia. High-income countries were not eligible. Although we aimed for geographical diversity, potential partners we had identified in the Middle East and Eastern Europe/Central Asia were not able to respond in the short space of time available to meet the application deadline for funding. 
Despite the estimated prevalence of dementia among people aged 60 and above ranging from 2 to 9 percent (Farina et al., 2020), and the number of people living with dementia being expected to increase dramatically in the upcoming decades (Global Observatory for Ageing and Dementia Care, 2015), services in the seven middle-income STRiDE countries are few and poorly coordinated. Only Indonesia and Mexico have NDPs (Alzheimer's Disease International, 2019a), for which funding has been limited and implementation restricted (Table 1).

Table 1 Characteristics of countries and current dementia plans and policies

\begin{tabular}{|c|c|c|c|c|c|c|c|c|}
\hline \multirow[t]{2}{*}{ Country } & \multirow[t]{2}{*}{$\begin{array}{l}\text { Populatio } \\
\mathrm{n} \\
\text { (millions) }^{1}\end{array}$} & \multirow[t]{2}{*}{$\begin{array}{l}\text { GDP } \\
\text { per } \\
\text { capita } \\
\text { (2011 } \\
\text { PPP\$) } \\
1\end{array}$} & \multirow[t]{2}{*}{$\begin{array}{l}\text { Word Bank } \\
\text { Income } \\
\text { Classificatio } \\
\mathrm{n}^{2}\end{array}$} & \multirow{2}{*}{$\begin{array}{l}\text { Age- } \\
\text { standardise } \\
\text { d } \\
\text { prevalence } \\
\text { of } \\
\text { dementia } \\
\text { for those } \\
\text { aged 60+ } \\
(\%)^{3}\end{array}$} & \multicolumn{2}{|c|}{$\begin{array}{l}\text { Estimated number of } \\
\text { people living with } \\
\text { dementia }\end{array}$} & \multirow[t]{2}{*}{$\begin{array}{l}\text { Dementia } \\
\text { plan or } \\
\text { policy exists } \\
\text { (yes/no/in } \\
\text { preparation } \\
\text { ) }^{4}\end{array}$} & \multirow[t]{2}{*}{$\begin{array}{l}\text { Dementia } \\
\text { plan/policy } \\
\text { implemented } \\
?^{4}\end{array}$} \\
\hline & & & & & $2015^{3}$ & $2050^{3}$ & & \\
\hline Brazil & 209.5 & $\begin{array}{l}14,28 \\
3\end{array}$ & $\begin{array}{l}\text { Upper } \\
\text { middle }\end{array}$ & 8.41 & $\begin{array}{l}1,620,00 \\
0\end{array}$ & $6,581,000$ & No & $\mathrm{N} / \mathrm{A}$ \\
\hline India & 1352.6 & 6,899 & $\begin{array}{l}\text { Lower } \\
\text { middle }\end{array}$ & 5.63 & $\begin{array}{l}4,092,00 \\
0\end{array}$ & $\begin{array}{l}12,580,00 \\
0\end{array}$ & No & $\mathrm{N} / \mathrm{A}$ \\
\hline $\begin{array}{l}\text { Indonesi } \\
\text { a }\end{array}$ & 267.7 & $\begin{array}{l}11,60 \\
6\end{array}$ & $\begin{array}{l}\text { Lower } \\
\text { middle }\end{array}$ & 7.15 & $\begin{array}{l}1,216,00 \\
0\end{array}$ & $4,299,000$ & Yes & $\begin{array}{l}\text { Partially } \\
\text { implemented }\end{array}$ \\
\hline Jamaica & 2.9 & 8,266 & $\begin{array}{l}\text { Upper } \\
\text { middle }\end{array}$ & 7.58 & 17,000 & 49,000 & No & $\mathrm{N} / \mathrm{A}$ \\
\hline Kenya & 51.4 & 3,077 & $\begin{array}{l}\text { Lower } \\
\text { Middle }\end{array}$ & 5.47 & 72,000 & 332,000 & No & N/A \\
\hline Mexico & 126.2 & $\begin{array}{l}18,10 \\
2 \\
\end{array}$ & $\begin{array}{l}\text { Upper } \\
\text { middle }\end{array}$ & 8.41 & 813,000 & $3,776,000$ & Yes & $\begin{array}{l}\text { Partially } \\
\text { implemented }\end{array}$ \\
\hline $\begin{array}{l}\text { South } \\
\text { Africa }\end{array}$ & 57.8 & $\begin{array}{l}12,14 \\
3\end{array}$ & $\begin{array}{l}\text { Upper } \\
\text { middle }\end{array}$ & 5.47 & 186,000 & 436,000 & No & N/A \\
\hline
\end{tabular}

1 United Nations Development Programme, 2018; ${ }^{2}$ World Bank, 2020, ${ }^{3}$ (Global Observatory for Ageing and Dementia Care, 2015), ${ }^{4}$ (Alzheimer's Disease International, 2019a) 
Theory of Change

Theory of Change (ToC) is a planning and evaluation approach which is increasingly used to describe, develop and visually map the path to intended impact of programmes and projects (De Silva et al., 2014; Vogel, 2012). This includes the:

1) impact or real-world change the project aims to achieve

2) short-, medium- and long-term outcomes which will be achieved by the project

3) activities which the project will implement to achieve these outcomes

4) rationale or evidence base for why these activities are likely to lead from one outcome to the next

5) assumptions about external conditions which are beyond the control of the project but necessary for the outcomes to occur

6) indicators which measure whether the outcomes have been achieved

7) ceiling of accountability: the point at which the project is responsible for the outcomes and after which outcomes are outside the scope of the funded project

A ToC is often developed through workshops with all the key stakeholders in the issue being addressed(Breuer et al., 2014). This ensures that the resulting ToC is plausible, achievable and creates a system of local accountability. The resulting ToC can have several purposes, including outlining strategic direction, and monitoring and evaluating progress to impact.

Although $\mathrm{ToC}$ is increasingly being used to plan and evaluate health-related programmes, examples of how this can be done in practice to develop both a strategic direction for a specific area of health or social care, as well as a programme theory for a specific research project, are limited(Breuer, Lee, De Silva, \& Lund, 2016). In this paper, we report on the process of ToC development using workshops and the resultant ToCs for the STRiDE project. A corresponding practical guide to conducting the workshop is available (Breuer, ComasHerrera, Docrat, Freeman, \& Schneider, 2019).

We used ToC to:

- Understand the strategic direction that the countries need to take to improve dementia care, treatment and support services

- Co-develop the project across and within STRiDE countries

- Develop a monitoring and evaluation framework for STRiDE activities; and

- Ensure stakeholder buy-in and knowledge exchange from the outset of the project.

\section{Stages of ToC development}

There were five stages in our ToC development process which resulted in an overarching STRiDE cross-country ToC and a series of country-level ToCs (Table 2): 
Table 2 Stages of ToC development

\begin{tabular}{|c|c|c|c|c|c|c|}
\hline Stages & ToC development & Date(s) & Length & Aims & Participants & Outputs \\
\hline 1. & $\begin{array}{l}\text { Initial cross-country } \\
\text { ToC workshop, } \\
\text { London, UK }\end{array}$ & March 2018 & $1 \frac{1}{2}$ days & $\begin{array}{l}\text { 1. Co-develop a logical STRiDE cross-country } \\
\text { ToC which outlines the impact and } \\
\text { pathways to impact for STRiDE research } \\
\text { and training } \\
\text { 2. Make explicit the assumptions and } \\
\text { evidence base underlying the ToC and } \\
\text { STRiDE project } \\
\text { 3. Generate research questions to answer } \\
\text { the assumptions and knowledge gaps } \\
\text { 4. Use the ToC to inform the STRiDE } \\
\text { monitoring and evaluation framework } \\
\text { 5. Ensure buy-in and knowledge exchange } \\
\text { across all STRiDE partners } \\
\text { 6. Build capacity of STRiDE partners to } \\
\text { conduct ToC workshops }\end{array}$ & $\begin{array}{l}\text { STRiDE partners (including leadership and all work } \\
\text { package leads, country researchers and NGO } \\
\text { representatives, Dementia Alliance International, } \\
\text { Alzheimer's Disease International) } \\
\text { World Health Organisation } \\
\text { Research Council UK Representative }\end{array}$ & $\begin{array}{l}\text { Draft STRiDE Cross- } \\
\text { country ToC } \\
\text { Monitoring and } \\
\text { evaluation } \\
\text { framework for } \\
\text { STRiDE }\end{array}$ \\
\hline 2. & $\begin{array}{l}\text { Within-country ToC } \\
\text { workshops }\end{array}$ & $\begin{array}{l}\text { April-July } \\
2018\end{array}$ & 1-2 days & $\begin{array}{l}\text { 1. Co-develop country level ToCs with } \\
\text { stakeholders which outlines the impact } \\
\text { and pathway to impact of STRiDE } \\
\text { 2. Ensure buy-in and knowledge exchange } \\
\text { within STRiDE countries } \\
\text { 3. Inform contextually feasible research } \\
\text { questions, tools, training needs, } \\
\text { contextual barriers and facilitating factors } \\
\text { and indicators to measure success }\end{array}$ & $\begin{array}{l}\text { Policymakers (government) (All countries) } \\
\text { Service planners and managers ( } 6 / 7 \text { countries) } \\
\text { Representatives of professional associations ( } 6 / 7 \\
\text { countries) } \\
\text { Service providers (All countries) } \\
\text { Researchers (All countries } \\
\text { Community and civil society (All countries) } \\
\text { People living with dementia (5/7 countries) and } \\
\text { their carers ( } 6 / 7 \text { countries) } \\
\text { (See Table } 3 \text { for details) }\end{array}$ & $\begin{array}{l}\text { STRiDE Country } \\
\text { ToCs (Web } \\
\text { Appendices 1-8) } \\
\text { Narrative Reports }\end{array}$ \\
\hline 3. & $\begin{array}{l}\text { Comparison } \\
\text { between STRiDE } \\
\text { Country and Project } \\
\text { ToCs }\end{array}$ & $\begin{array}{l}\text { September } \\
2018\end{array}$ & $\begin{array}{l}2 \times 2 \text { hour } \\
\text { Skype } \\
\text { meeting }\end{array}$ & $\begin{array}{l}\text { 1. Compare STRiDE cross-country ToC with } \\
\text { country ToC maps and refine STRiDE } \\
\text { cross-country ToC }\end{array}$ & $\begin{array}{l}\text { Core team (Breuer, Commas-Herrera, Freeman and } \\
\text { Schneider) }\end{array}$ & $\begin{array}{l}\text { Final STRiDE Cross- } \\
\text { country ToC (Web } \\
\text { Appendix 1) }\end{array}$ \\
\hline 4. & $\begin{array}{l}\text { Comparison with } \\
\text { WHO guidelines }\end{array}$ & $\begin{array}{l}\text { February } \\
2019\end{array}$ & $\begin{array}{l}1 \frac{1 / 2}{2} \text { hour } \\
\text { Skype } \\
\text { meeting }\end{array}$ & $\begin{array}{l}\text { 1. Compare STRiDE cross-country ToC with } \\
\text { WHO action plan and guidance and refine } \\
\text { STRiDE cross-country ToC }\end{array}$ & $\begin{array}{l}\text { Core team (Breuer, Commas-Herrera, Freeman and } \\
\text { Schneider) }\end{array}$ & \\
\hline 5. & $\begin{array}{l}\text { Final review, Cape } \\
\text { Town, South Africa }\end{array}$ & March 2019 & $45 \min$ & $\begin{array}{l}\text { 1. Final approval of STRiDE Cross-country } \\
\text { ToC map from STRiDE partners }\end{array}$ & $\begin{array}{l}\text { STRiDE partners including representatives from all } \\
\text { STRiDE countries and chair of the International } \\
\text { Advisory Group }\end{array}$ & \\
\hline
\end{tabular}




\section{Stage 1: Initial cross-country STRIDE ToC development workshop}

We held a two-day ToC workshop with all STRiDE partners in March 2018 (Tables 2 \& 3). The aim of the workshop was to produce a visual representation (ToC map) of the pathway to achieving STRiDE's intended impact: that people with dementia and their carers live well and do not shoulder excessive costs, risk impoverishment or health problems (Figure 1, Web Appendix 1) by making explicit the short-, medium- and long-term outcomes of the project and STRiDE activities which are expected to lead to the outcomes. The workshop also provided important training to enable the teams based in STRiDE countries to conduct further within-country ToC workshops (Stage 2).

During the workshop, STRiDE partners identified challenges in developing appropriate care, treatment and support systems for people with dementia and their unpaid carers. Partners raised issues associated with:

a) legal systems and understanding of ethics and human rights;

b) government and donor priorities, policy and politics, and the availability of financial resources;

c) workforce and health and social care organisation;

d) identification of dementia, treatment and care, including end of life care;

e) lack of research evidence;

f) expectations of familial care (often 'informal' or 'unpaid') and other social norms;

g) lack of knowledge, shame and stigma associated with dementia; and

h) the lack of involvement of people living with dementia in decision making.

We discussed STRiDE's intended impact, as set out in the initial grant proposal: that people with dementia and their carers live well and do not shoulder excessive costs, risk impoverishment or health problems, and after discussion agreed that this was a suitable impact statement for the STRiDE ToC. Then, working in small across-country groups, we considered the steps (outcomes) to achieve this impact in light of these challenges.

Outcomes were mapped onto a ToC map, and connections between them were identified. We mapped both outcomes that needed to be achieved by STRiDE and those which were necessary to achieving the impact beyond STRIDE. This resulted in two distinct sections of the ToC, separated by the ceiling of accountability. The STRiDE activities, divided into ten work packages, which are expected to lead to the outcomes, were then additionally mapped.

After the first workshop day, the ToC model developed by hand was drawn electronically (by Breuer) and reviewed by a core group of authors (Breuer, Commas-Herrera, Freeman and Schneider). This model was then distributed to workshop participants in the second workshop day. Again, working in small groups, participants reviewed the model, gave feedback on items and relationships as drawn, checked the logical plausibility of the ToC, and highlighted the assumptions implicit in it. Finally, participants discussed how the outcomes which would be achieved by STRIDE could be measured. The indicators identified 
were refined after the workshops, and are now being used to regularly monitor and evaluate the STRiDE project (see Web Appendix 1 for details). 
Table 3 Number and type of stakeholders represented in STRIDE TOC workshops (one stakeholder could fall into more than one category)

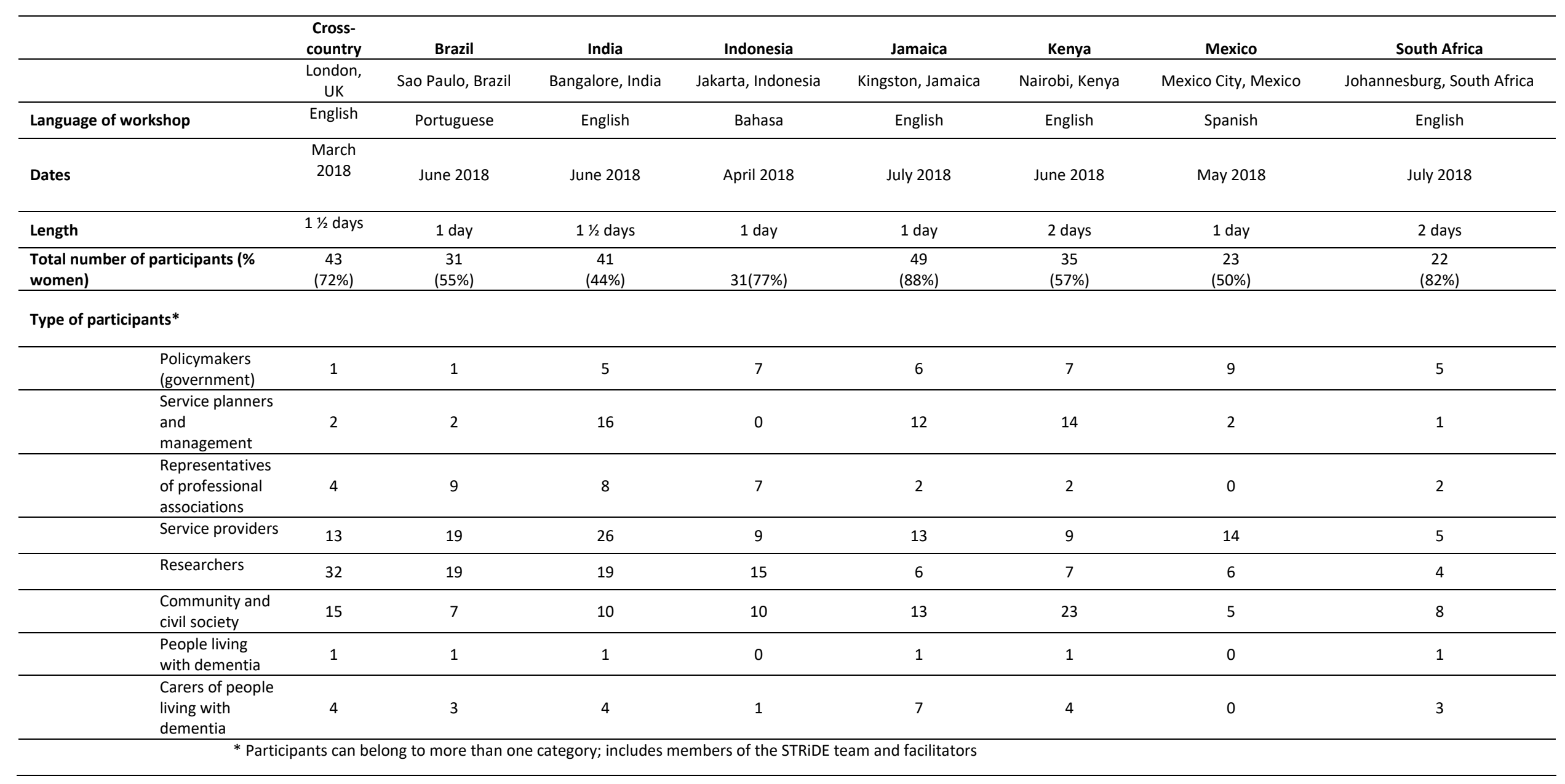




\section{Stage 2: Within-country STRIDE Country ToC Development Workshops}

We held a single two-day ToC workshop in each of the STRiDE countries between April and July 2018 (Tables 2 \& 3). Workshops were facilitated by STRiDE teams based in each country, with support from the core ToC team where requested.

Within-country workshops were similarly structured. All began with a formal welcome and introductions to participants, the dementia situation within the country, the STRiDE project, and the ToC process. Initially working in small groups, participants considered countryspecific challenges related to dementia, followed by the potential impact of STRiDE. Country workshops afforded opportunity to assess, verify and revise the STRIDE impact statement agreed on at the cross-country workshop, ensuring the project is locally relevant. For example, in Kenya, participants felt the impact was too broad, so explicated it accordingly: to achieve improved dementia prevention, care, treatment and support systems so that people with dementia, carers and family have highest possible wellbeing and functional ability.

As in the cross-country workshop, the within-country workshops focused on pathways to achieving impact within and beyond STRIDE, as well as the contribution of STRiDE activities to that impact. In some countries, additional sessions in the workshop aimed to help participants clearly understand local context and the extent of dementia care services. For example, in India, we wanted to ensure our ToC reflected the existing research, care and services addressing dementia, so invited stakeholders to speak about their own work.

Despite the different social, political, economic and health systems and norms in the seven STRiDE countries, many of the key workshop discussions were similar. Recurring themes were:

1) lack of government commitment and leadership,

2) the need for evidence-based dementia care programmes

3) the need for earlier diagnosis

4) inadequate long-term care systems

5) the importance of including people living with dementia in decision-making,

6) poor knowledge of dementia

7) the stigmatisation of dementia, and

8) reliance on gendered informal care (typically female and family-based) (See Table 4, Web Appendices 2-8).

As illustrated, despite similarities, some issues were salient only in particular countries. For example, the inequitable distribution and funding of services across private and public 
sectors was raised most strongly by the Brazilian workshop participants; only South African and Kenyan participants noted understandings of witchcraft and dementia as a dominant concern.

In most countries, the ToC workshop was the first multisectoral forum relating to dementia, which allowed stakeholders to exchange perspectives and work together towards one objective. In five countries (Brazil, India, Jamaica, Kenya, and South Africa), the workshop was the first forum to have included people living with dementia, an important milestone in the inclusion of people living with dementia in care planning. The continued engagement and perspectives of stakeholders in the STRIDE project was secured by inviting some workshop participants to become part of National Advisory Groups. The role of these groups is to advise on the feasibility and relevance of STRiDE activities in each country, holding teams accountable for their activities, and advocating for local dementia research and initiatives.

Following the workshops, ToCs were finalised by teams based in each country, with support from the core international $\mathrm{ToC}$ team. $\mathrm{A} \mathrm{ToC}$ and a narrative report of the process were produced in each country (see Web Appendices 2-8).

\section{Stage 3: Comparison between STRiDE cross-country ToC and National ToCs}

The core ToC team reviewed country ToCs and narrative reports to ensure that the overall STRiDE cross-country ToC reflected national priorities and pathways. These were discussed via two teleconferences, and changes were made to the cross-country ToC. Changes included phrasing and connections between outcomes. For example, People with dementia are seen as individuals and enabled to continue to contribute actively to society, make choices and to live with dignity was changed to People with dementia are empowered to seek help early, be seen as individuals and enabled to continue to contribute actively to society, make choices and to live and die with dignity.

\section{Stage 4: Comparison between STRIDE cross-country ToC and WHO Guidance}

The core ToC team next reviewed the project ToC against the Global action plan on the public health response to dementia 2017-2025 (World Health Organization, 2017) and Towards a dementia plan: a WHO guide (World Health Organization, 2018) to ensure that outcomes were in alignment. Required changes were minor, consisting mainly of clarifying the wording of outcomes. The only aspect of the WHO guidance not reflected in the STRIDE cross-country $\mathrm{ToC}$ is primary prevention and cure. Participants at the initial cross-country workshop considered these to be beyond the scope of the project and its ToC.

\section{Stage 5: STRIDE cross-country ToC Final Review}

The draft STRiDE cross-country ToC was presented to all partners and the chair of the STRiDE International Advisory Group at the project's Annual Meeting in March 2019. The final ToC, outlined below, reflects additional minor changes suggested by the group. For 
example, adding the word assessment to Policy makers across sectors are convinced that actions to improve dementia prevention, assessment, care, treatment and support are a priority. In order to compare the ToCs across countries, we developed themes which grouped several outcomes together (Table 4).

\section{Final STRiDE cross-country ToC}

The final STRiDE cross-country ToC (Figure 1 and Web Appendix 1) is divided into two distinct sections by the ceiling of accountability (the point after which the project is no longer responsible for achieving the outcomes). On the left of the ceiling of accountability is the STRiDE project ToC and on the right is the ToC of what will be needed in STRiDE countries to build on the project's outcomes and activities so that people with dementia and their carers live well.

\section{1) STRiDE Project ToC}

The left side of the ceiling of accountability resembles a standard project ToC, outlining the outcomes STRiDE is responsible for achieving related to the following themes: project functioning, research capacity, evidence, knowledge, awareness and knowledge exchange, collaboration between multiple stakeholders and inclusion of people living with dementia, and stigma (Table 4). It outlines activities (STRiDE work-packages) which will ensure that the project achieves its outcomes. This section of the ToC forms the basis of the monitoring and evaluation framework for STRiDE (see Figure 1 and Web Appendix 1).

2) ToC for the strategic direction for dementia care, treatment and support in LMICs To the left side of ceiling of accountability, the ToC describes the hypothesised outcomes necessary for STRIDE countries to build on the project's outcomes and activities so that people with dementia and their carers live well. This can also be seen as a ToC for developing and implementing government-led NDPs. Outcomes in this section of the ToC can be categorised into the following themes: inclusion of people living with dementia, stigma, policy and plans, accountability, data and monitoring, prioritization of dementia and political will, government leadership, financing, health and social care systems and guidelines, workforce and training, identification and treatment/care and unpaid care. Within this section the evidence and recommendations generated by the STRiDE work packages are mapped as the rationale underpinning the ToC.

Like the cross-country ToC, each within-country ToC has two distinct sections divided by a ceiling of accountability. The first section (to the left of the ceiling of accountability) outlines the activities and outcomes which are the responsibility of the STRiDE project and the second section identifies the outcomes required to develop adequate dementia care and services nationally. These are the responsibility of the governments in the STRiDE countries but will be informed by evidence generated by STRiDE. Major themes reflected in the STRiDE country ToCs include evidence, knowledge awareness and exchange, inclusion of 
people living with dementia, dementia policy and plans, accountability, governance, data, treatment and care. Table 4 compares the outcome themes and impacts across STRiDE country and cross-country ToCs. 


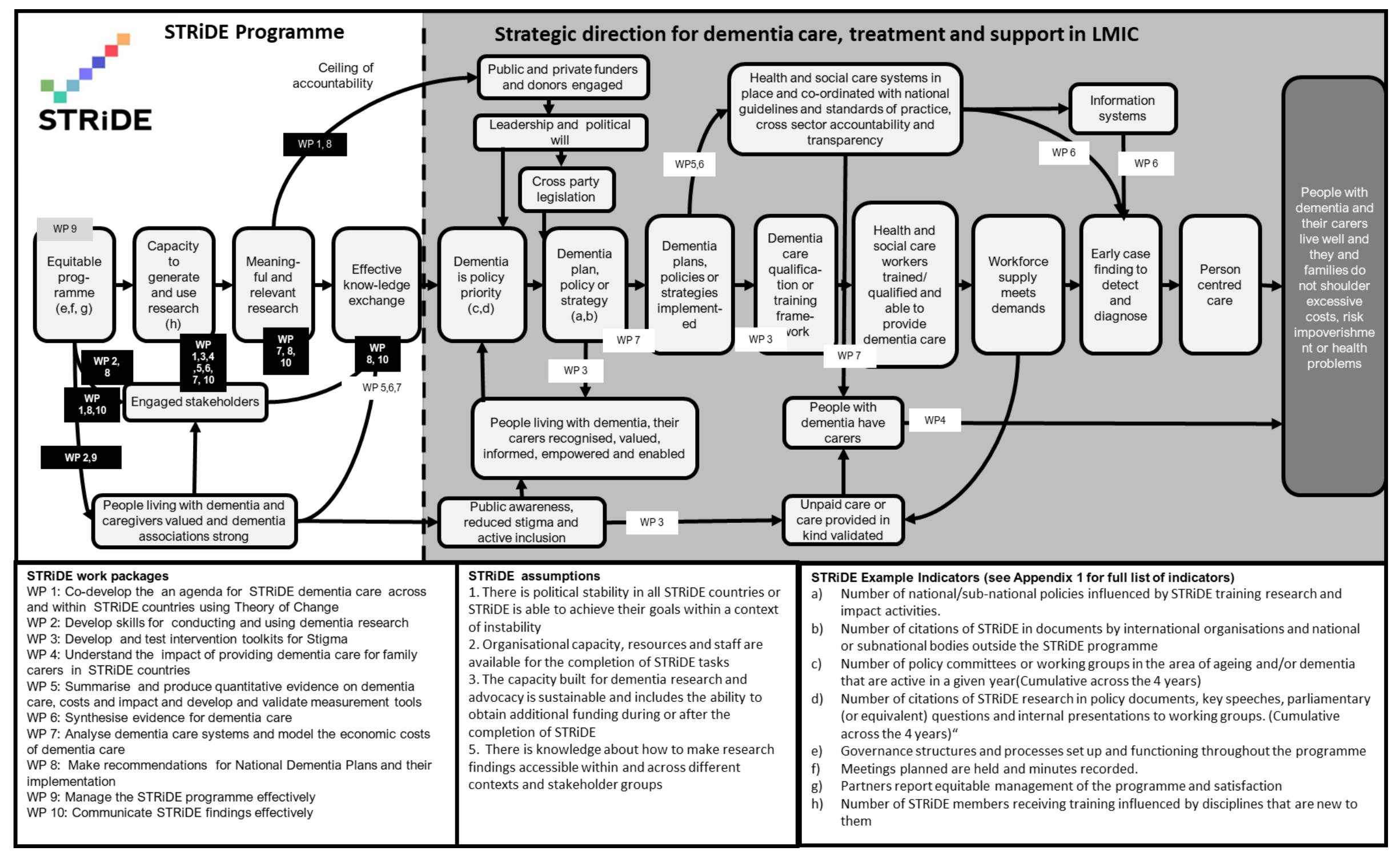

Figure 1 STRiDE abbreviated ToC. See Web Appendix 1 for full ToC 
Table 4 Themes covered by outcomes in the STRIDE TOCs. Black dots refer to themes represented before the ceiling of accountability and the white dot after the ceiling of accountability

\begin{tabular}{|c|c|c|c|c|c|c|c|c|}
\hline & \multirow{2}{*}{$\begin{array}{c}\text { STRiDE } \\
\text { Cross- } \\
\text { country } \\
\text { ToC } \\
\end{array}$} & \multicolumn{7}{|c|}{ Country ToC } \\
\hline & & Brazil & India & Indonesia & Jamaica & Kenya & Mexico & South Africa \\
\hline \multicolumn{9}{|l|}{ Outcome themes } \\
\hline $\begin{array}{l}\text { Project } \\
\text { functioning }\end{array}$ & $\bullet$ & & & & & & & \\
\hline $\begin{array}{l}\text { Research } \\
\text { capacity }\end{array}$ & • & & & & & & & \\
\hline Evidence & $\bullet$ & $\bullet$ & $\bullet$ & $\bullet$ & $\bullet$ & $\bullet$ & $\bullet$ & $\bullet$ \\
\hline $\begin{array}{l}\text { Knowledge, } \\
\text { awareness and } \\
\text { knowledge } \\
\text { exchange }\end{array}$ & $\bullet$ & $\bullet$ & $\bullet$ & $\bullet$ & $\bullet$ & $\bullet$ & $\bullet$ & $\bullet$ \\
\hline $\begin{array}{l}\text { Collaboration } \\
\text { between } \\
\text { multiple } \\
\text { stakeholders }\end{array}$ & $\bullet$ & $\bullet$ & & O & $\bullet$ & $\bullet$ & & $\bullet$ \\
\hline $\begin{array}{l}\text { Inclusion of } \\
\text { people living } \\
\text { with dementia, } \\
\text { and stigma }\end{array}$ & $\bullet$ & $\bullet$ & $\bullet$ & $\bullet$ & $\bullet$ & $\bullet$ & 0 & O \\
\hline Policy and plans & 0 & O & 0 & 0 & O & $\bullet$ & 0 & $\bullet$ \\
\hline $\begin{array}{l}\text { Accountability, } \\
\text { data and } \\
\text { monitoring }\end{array}$ & O & - 0 & O & O & & $\bullet$ & O & O \\
\hline $\begin{array}{l}\text { Prioritization of } \\
\text { dementia and } \\
\text { political will }\end{array}$ & O & O & & $\bullet$ & $\bullet$ & & $\bullet$ & O \\
\hline $\begin{array}{l}\text { Government } \\
\text { leadership }\end{array}$ & O & O & $\bullet$ & & & & O & \\
\hline Financing & 0 & O & & & & & O & 0 \\
\hline $\begin{array}{l}\text { Health and } \\
\text { social care } \\
\text { systems and } \\
\text { guidelines }\end{array}$ & O & & O & O & O & $\bullet$ & 0 & \\
\hline $\begin{array}{l}\text { Workforce and } \\
\text { training }\end{array}$ & O & O & 0 & O & & & O & \\
\hline $\begin{array}{l}\text { Identification } \\
\text { and } \\
\text { treatment/care }\end{array}$ & O & - 0 & $\bullet$ & O & O & $\bullet$ & O & O \\
\hline
\end{tabular}




\begin{tabular}{|c|c|c|c|c|c|c|c|c|c|}
\hline & \multirow{2}{*}{$\begin{array}{c}\text { STRiDE } \\
\text { Cross- } \\
\text { country } \\
\text { ToC }\end{array}$} & \multicolumn{8}{|c|}{ Country ToC } \\
\hline & & Brazil & \multicolumn{2}{|c|}{ India } & Indonesia & Jamaica & Kenya & Mexico & South Africa \\
\hline Unpaid care & 0 & 0 & \multicolumn{2}{|c|}{$\bullet$} & 0 & & & & \\
\hline & Impact(s) & $\begin{array}{l}\text { 1) People with } \\
\text { dementia and their } \\
\text { carers live well; and } \\
\text { 2) People with } \\
\text { dementia and } \\
\text { families do not } \\
\text { shoulder excessive } \\
\text { costs, risk } \\
\text { impoverishment or } \\
\text { health problems }\end{array}$ & $\begin{array}{l}\text { People with } \\
\text { dementia, } \\
\text { their carers } \\
\text { and families } \\
\text { live and die } \\
\text { well }\end{array}$ & $\begin{array}{l}\text { To contribute to reducing } \\
\text { risk, improving dementia } \\
\text { diagnosis, management } \\
\text { and support systems, so } \\
\text { that people with } \\
\text { dementia are able to live } \\
\text { well, and that their family, } \\
\text { carers and society are } \\
\text { protected from excessive } \\
\text { costs and health } \\
\text { problems; and 3) Carers } \\
\text { of people living with } \\
\text { dementia have the } \\
\text { capacity and are } \\
\text { supported to provide } \\
\text { quality care for people } \\
\text { living with dementia }\end{array}$ & $\begin{array}{l}\text { People with } \\
\text { dementia, } \\
\text { carers and } \\
\text { family are } \\
\text { able to live } \\
\text { well }\end{array}$ & $\begin{array}{l}\text { 1) People living with } \\
\text { dementia and their } \\
\text { carers live optimally; 2) } \\
\text { people living with } \\
\text { dementia and their } \\
\text { carers do not shoulder } \\
\text { excessive financial } \\
\text { burden (e.g. they } \\
\text { access: affordable } \\
\text { formal and informal } \\
\text { healthcare); } 3 \text { ) Carers } \\
\text { of persons living with } \\
\text { dementia have the } \\
\text { capacity and are } \\
\text { supported to provide } \\
\text { quality care for persons } \\
\text { living with dementia }\end{array}$ & $\begin{array}{l}\text { Improved } \\
\text { dementia } \\
\text { prevention, care, } \\
\text { treatment and } \\
\text { support systems } \\
\text { so that people } \\
\text { with dementia, } \\
\text { carers and family } \\
\text { have highest } \\
\text { possible } \\
\text { wellbeing and } \\
\text { functional ability }\end{array}$ & $\begin{array}{l}\text { 1) People with } \\
\text { dementia and their } \\
\text { carers live well; and } \\
\text { 2) People with } \\
\text { dementia and } \\
\text { families do not } \\
\text { shoulder excessive } \\
\text { costs, risk } \\
\text { impoverishment or } \\
\text { health problems }\end{array}$ & $\begin{array}{l}\text { 1) The ability of } \\
\text { people with } \\
\text { dementia to } \\
\text { live a } \\
\text { meaningful } \\
\text { and dignified } \\
\text { life is } \\
\text { maximised. } \\
\text { 2) Family and } \\
\text { carers have the } \\
\text { necessary } \\
\text { support and } \\
\text { resources for } \\
\text { well-being and } \\
\text { to be } \\
\text { protected from } \\
\text { undue financial } \\
\text { hardship }\end{array}$ \\
\hline
\end{tabular}




\section{Lessons learned}

1. ToC can be used to develop a common vision for dementia care, treatment and support among diverse stakeholders

The ToC approach helped the STRIDE team to co-develop a common vision of the strategic direction for dementia care and services in middle-income countries. STRiDE partners come from different world regions (Europe, The Caribbean, Central and South America, SubSaharan Africa and Asia), different fields (economics, epidemiology, demography, geriatrics, neurology, mental health, policy, health services research, long-term care research), national and international Alzheimer's and dementia associations and people living with dementia, among others. Within-country workshops brought together national stakeholders who, by design, were external to STRiDE. The series of ToC workshops required all participants to pool knowledge about challenges related to dementia as well as previous experiences in their field, and work together to identify steps to mitigate these challenges both within and beyond the scope of STRiDE.

Because the ToC workshop is a structured event with the specific goal of developing a ToC map, it gives stakeholders a sense of purpose and direction. The task-orientated nature of the ToC workshops encouraged participants to maintain focused discussions. Where possible, the structure of the workshops facilitated the active participation of people living with dementia and their carers.

2. The proposed contribution of the project and broader strategic direction for dementia care, treatment and support should be clearly delineated

A risk and a strength of the ToC approach is the necessity for stakeholders to think broadly and creatively about achieving an impact. Participants at both cross-country and withincountry ToC workshops developed ambitious ToCs outlining the strategic direction for dementia over the longer-term. However, since STRIDE is a four-year project with specific research and capacity-building objectives, its role needed to be clearly delineated. This was particularly important in the country workshops with 'external' participants who expected STRiDE to have a larger role. We used our ceiling of accountability to clearly delineate STRiDE, government, and NGO responsibilities for treatment, care and support for dementia. The workshops have already prompted action by Government and NGO stakeholders to establish a National Dementia Working Group in South Africa and to develop a national dementia plan in Kenya. 
3. People living with dementia should be included in ToC workshops in LMIC, but additional support will be required

The rights of people living with dementia and their carers to participate in research and programme planning as 'experts by experience' is increasingly being recognized in many high-income countries (Gove et al., 2018). This has not been common in the seven middleincome STRIDE countries. Reasons for this include low societal awareness of dementia, latestage diagnosis when the person living with dementia has severely reduced functional abilities (Prince, Comas-Herrera, Knapp, Guerchet, \& Karagiannidou, 2016), high levels of stigma-related to dementia (Alzheimer's Disease International, 2019b; Herrmann et al., 2018), and non-disclosure of dementia diagnosis (Raicher, Shimizu, Takahashi, Nitrini, \& Caramelli, 2008).

We invited people living with dementia to all our ToC workshops but were unable to secure their participation in two of the country workshops due to stigma related concerns from people living with dementia about sharing their diagnosis and experiences in public. As noted above, workshops were structured to facilitate the active participation of people living with dementia and their carers (e.g. using small groups and specifically eliciting input). In India, a psychologist was paired with the participant living with dementia and their carer throughout the workshop to encourage participation and monitoring for signs of stress. On the other hand, in Jamaica, the participant with dementia was given the freedom to observe and participate in workshop activities before choosing whether or not to disclose their diagnosis. The participant later decided to address the workshop and to take questions.

\section{Conclusion}

Our experience of using the ToC approach in STRiDE highlights how ToC can provide a framework to foster international multidisciplinary collaboration to outline a strategic direction for dementia care and policy. We used ToC workshops to bring together diverse stakeholders, including people living with dementia, in order to develop both a common vision for, and buy-in to the STRiDE project and broader dementia care, as well as to help clearly delineate the areas for which STRIDE is accountable. Additional strategies may be needed to ensure appropriate participation from people living with dementia and their carers in the ToC process. The ToC approach, using the STRIDE ToC as a starting point, could provide governments in LMICs an approach to inclusive planning with and for people living with dementia to understand to how ensure that people with dementia live well. 


\section{List of abbreviations}

ToC: Theory of Change

NDP: National Dementia Plans

LMIC: low- and middle-income countries

ADI: Alzheimer's Disease International

DAI: Dementia Alliance International

WHO: World Health Organization

\section{Patient and public involvement}

The planning process described in this paper involved people living with dementia, their carers and members of non-governmental organisations. Representatives of these groups were involved in the workshops, providing feedback and in the writing and reviewing of this paper.

\section{Data Sharing}

Data sharing is not applicable to this paper.

\section{Ethical Considerations}

This paper does not include research on human subjects and therefore we did not obtain ethical approval.

\section{Acknowledgments}

We acknowledge all the contributions of all the stakeholders who attended the STRiDE ToC workshops and gave input into the STRiDE ToC development process.

\section{Declaration of Interest}

WW and ML are employed by Alzheimer's Disease International (ADI) who receive funding from several pharmaceutical companies (see https://www.alz.co.uk/sponsors for details). The funding is related to the work of STRIDE, and the STRiDE work is not directly relevant to ADI's funders.WW received honoraria from Eisai and Roche for presentations outside the submitted work. No other authors report a conflict of interest. 


\section{Funding}

This work was supported by the UK Research and Innovation's Global Challenges Research Fund (ES/P010938/1)

\section{References}

Alzheimer's Disease International. (2019a). Dementia plans. Retrieved from https://www.alz.co.uk/dementia-plans

Alzheimer's Disease International. (2019b). World Alzheimer Report 2019: Attitudes to dementia. Retrieved from London:

Breuer, E., Comas-Herrera, A., Docrat, S., Freeman, E., \& Schneider, M. (2019). STRiDE Theory of Change Workshops: Guidance and Resources. STRiDE Research Tool No.1 (version 2). Retrieved from https://www.stride-dementia.org/publications

Breuer, E., De Silva, M. J., Fekadu, A., Luitel, N. P., Murhar, V., Nakku, J., . . Lund, C. (2014). Using workshops to develop theories of change in five low and middle income countries: lessons from the programme for improving mental health care (PRIME). International Journal of Mental Health Systems, 8(1), 15. doi:10.1186/1752-4458-8-15

Breuer, E., Lee, L., De Silva, M., \& Lund, C. (2016). Using theory of change to design and evaluate public health interventions: a systematic review. Implementation Science, 11(1), 63. doi:10.1186/s13012-016-0422-6

De Silva, M. J., Breuer, E., Lee, L., Asher, L., Chowdhary, N., Lund, C., \& Patel, V. (2014). Theory of Change: a theory-driven approach to enhance the Medical Research Council's framework for complex interventions. Trials, 15(1), 267. doi:10.1186/1745-6215-15-267

Farina, N., Ibnidris, A., Alladi, S., Comas-Herrera, A., Albanese, E., Docrat, S., . . Banerjee, S. (2020). A systematic review and meta-analysis of dementia prevalence in seven developing countries: A STRiDE project. Glob Public Health, 15(12), 1878-1893. doi:10.1080/17441692.2020.1792527

Global Observatory for Ageing and Dementia Care. (2015). Unpublished data from the World Alzheimer Report 2015

Gove, D., Diaz-Ponce, A., Georges, J., Moniz-Cook, E., Mountain, G., Chattat, R., . . Dementia, E. W. G. o. P. w. (2018). Alzheimer Europe's position on involving people with dementia in research through PPI (patient and public involvement). Aging Ment Health, 22(6), 723-729.

Herrmann, L. K., Welter, E., Leverenz, J., Lerner, A. J., Udelson, N., Kanetsky, C., \& Sajatovic, M. (2018). A Systematic Review of Dementia-related Stigma Research: Can We Move the Stigma Dial? Am J Geriatr Psychiatry, 26(3), 316-331. doi:10.1016/j.jagp.2017.09.006

London School of Economics and Political Science. (2020). STRiDE: Strengthening responses to dementia in developing countries Retrieved from https://www.stride-dementia.org/

Prince, M. (2015). World Alzheimer Report 2015: the global impact of dementia: an analysis of prevalence, incidence, cost and trends. Retrieved from

Prince, M., Comas-Herrera, A., Knapp, M., Guerchet, M., \& Karagiannidou, M. (2016). World Alzheimer report 2016: improving healthcare for people living with dementia: coverage, quality and costs now and in the future.

Raicher, I., Shimizu, M. M., Takahashi, D. Y., Nitrini, R., \& Caramelli, P. (2008). Alzheimer's disease diagnosis disclosure in Brazil: a survey of specialized physicians' current practice and attitudes. International Psychogeriatrics, 20(3), 471-481. doi:10.1017/S1041610207005819 
Vogel, I. (2012). Review of the use of 'Theory of Change' in international development. Retrieved from UK:

World Health Organization. (2017). Global action plan on the public health response to dementia 2017-2025.

World Health Organization. (2018). Towards a dementia plan: a WHO guide. 